\title{
Distal Foot Reconstruction Using Distally based First Web Flap:
}

\section{A Case Series}

\author{
Mohan R, Kumar N*, Manoj KJ, Umesh N and Kumar A
}

Department of Burns, Pgimer \& Dr. R.M.L. Hospital, India

*Corresponding author: DR. Naveen Kumar (Ms, Mch Std.), Senior Resident, Department of Burns, Plastic \& Reconstructive Surgery, Pgimer \& Dr. R.M.L. Hospital, New Delhi -110001, India, Tel: 9968262759; Email: drnaveenvmmc@gmail.com

\section{Research article}

Volume 3 Special Issue 2

Received Date: May 15, 2019

Published Date: May 27, 2019

DOI: $10.23880 /$ ijtps-16000S2-005

\section{Abstract}

Background: The reconstruction of distal foot for various defects or contractures mainly over or near the toes has always been a difficult task. A flap distally based on first web space is dependent upon a perforator arising from the distal communications between the first dorsal and plantar metatarsal arteries, can be used for the coverage of the toe or the distal foot defects.

Method: We had operated 10 patients with toe defects and contractures at the dorsum of the distal foot . Demographic data of the patients were collected and evaluated in terms of age, gender, etiology of injury, site and dimensions of defects, complications, final outcome.

Results: Complications were noted in only two cases in the form of wound infections. Both the cases were managed accordingly.

Conclusion: With our study we concluded that a distally based flap can be reliably raised from the first web space based upon a perforator arising from the distal communication artery between First Dorsal and First Plantar Metatarsal Artery to cover defects in distal foot.

Keywords: Foot Defects; Toe; Distal Communicating Artery; Dorsalis Pedis Artery; First Dorsal Metatarsal Artery

Abbreviations: FDMA: First Dorsal Metatarsal Artery; DCA: Distal Communicating Artery; DPA: Dorsalis Pedis Artery; PMTA: Plantar Metatarsal Artery; DMTA: Dorsal Metatarsal Artery.

Declaration: The study is in accordance with the ethical standards of the responsible committee on human experimentation (Institutional or Regional) and with the Helsinki declaration of 1975, as revised in 2000.

\section{Introduction}

The reconstruction of distal foot for various defects or contractures mainly over or near the toes has always been a difficult task to accomplish in the field of plastic and reconstructive surgery [1]. Not much option is available to correct the defects at these sites. Among the available options, commonly used options are skin graft, random pattern flap; cross-leg flap and free flaps $[2,3]$.

The skin grafts are of limited use as these are not suitable to cover the tendons or the exposed bone and besides this skin grafts show the tendency to contract making flaps more of a reliable option to cover the defects created following release of the contractures [4]. Other flaps may not be as suitable as our mentioned flap owing to the factors such as these are at times bulky, unreliable, involving microsurgical techniques and expertise and 


\section{International Journal of Transplantation \& Plastic Surgery}

lastly the need of patient positioning in an uncomfortable way. A flap distally based on first web space dependent upon a perforator arising from the distal communications between the first dorsal and plantar metatarsal arteries, can be used for the coverage of the toe or the distal foot defects.

\section{Material and Methods}

We had operated 10 patients with toe defects and contractures at the dorsum of the distal foot who were admitted in the department of burns and plastic surgery at our institute between periods of August 2016 to August 2018. It was an observational study with case series. Informed consent was obtained from all the patients. Demographic data of the patients were collected and evaluated in terms of age, gender, etiology of injury, site and dimensions of defects, complications, final outcome (Table 1).

\begin{tabular}{|c|c|c|c|c|c|c|}
\hline S.No & $\begin{array}{c}\text { Age } \\
\text { (years) }\end{array}$ & $\begin{array}{c}\text { Defect size } \\
\text { (cm sq.) }\end{array}$ & Etiology & $\begin{array}{c}\text { Post - op } \\
\text { complications }\end{array}$ & Final outcome \\
\hline 1 & 35 & Right forefoot(dorsal aspect) & $5 \times 4$ & Post burn contracture & None & Complete Healing \\
\hline 2 & 50 & Left great toe & $2 \times 2$ & Crush injury & None & Complete Healing \\
\hline 3 & 25 & Left great foot & $5 \times 5$ & Post burn contracture & None & Complete Healing \\
\hline 4 & 40 & Right forefoot(dorsal aspect) & $4 \times 3$ & Post burn contracture & None & Complete Healing \\
\hline 5 & 48 & Right great toe & $6 \times 5$ & Road traffic accident & Wound Infection & Complete Healing \\
\hline 6 & 18 & Left great foot & $2 \times 1$ & Crush injury & None & Complete Healing \\
\hline 7 & 22 & Right forefoot(dorsal aspect) & $4 \times 2$ & Post burn contracture & None & Complete Healing \\
\hline 8 & 16 & Right forefoot(dorsal aspect) & $5 \times 3$ & Post burn contracture & None & Complete Healing \\
\hline 9 & 37 & Right forefoot(dorsal aspect) & $3 \times 2$ & Road traffic accident & None & Complete Healing \\
\hline 10 & 46 & Left great foot & $4 \times 4$ & Road traffic accident & Wound Infection & Complete Healing \\
\hline
\end{tabular}

Table 1: Demographic data of the patients who underwent foot reconstruction with distally based first web space flap.

The indications for flap coverage were the exposure of vital tissues such as tendons, bone joints and defect size amenable to local flap cover.
All cases were evaluated beforehand using physical and Doppler examinations.

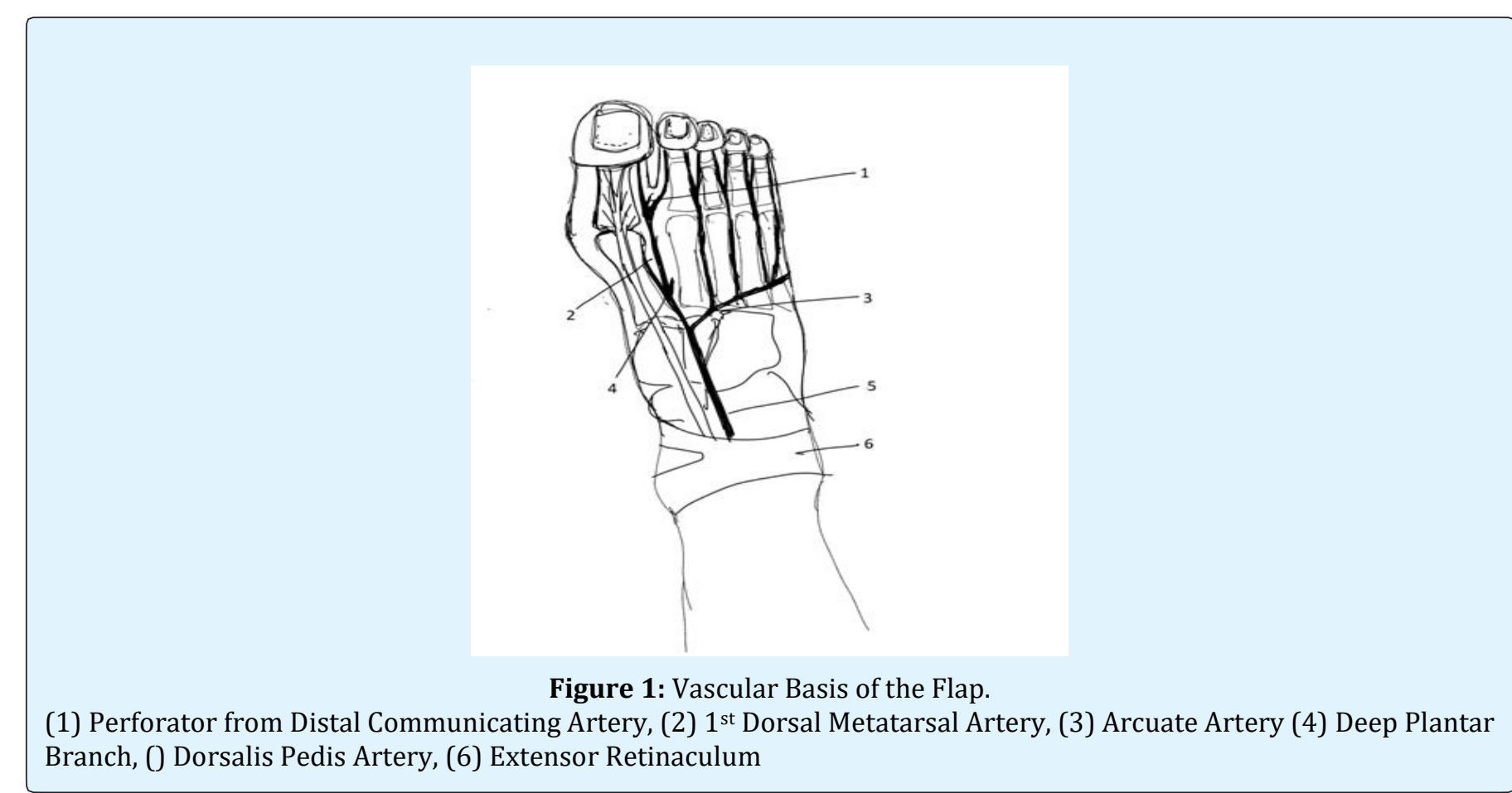




\section{International Journal of Transplantation \& Plastic Surgery}

Blood supply of the foot usually derived from anterior and posterior tibial arteries. The dorsal and plantar arches join these two arteries. The anterior tibial artery continues as the Dorsalis pedis artery (DPA) passing below the extensor retinaculum, which ends as the first dorsal metatarsal artery (FDMA) after giving off the plantar branch [1]. It also gives off abundant cutaneous arteries, muscular branches and lateral and medial tarsal branches between the extensor retinaculum and the deep plantar branch [2] .The FDMA after coursing through the first intermetatarsal space, passes dorsal to the transverse metatarsal ligament and divides into two dorsal digital arteries to the toes. There was a constant anastomotic branching between the FDMA and first plantar metatarsal artery PMTA passing distal to the transverse metatarsal ligament [4]. These branches have been named the distal (or anterior) communicating arteries [3,4]. An adequate arterial inflow can be provided by a perforator arising from the distal communicating artery from the plantar system which forms the basis for raising the reliable flaps in our study. The FDMA, the DCA and the common digital vessels give rise to cutaneous vessels in the distal web-space. The viability of any flap depends upon these first web arterial branches included in its subcutaneous pedicle [4].

\section{Surgical Technique}

A preoperative Doppler examination had evaluated the blood flow of the DPA, the plantar artery, the FDMA and the perforator arising from the DCA. Pivot point of the flap was marked for the unnamed perforator in the first web space just ulnar to the first metatarsophalengeal joint distal to the transverse metatarsal ligament. A pneumatic tourniquet was applied and the skin incision was started from the proximal side of the flap. The flap was raised as a random cutaneous one with base to length ratio of $1: 3$ or more, keeping a generously thick base distally. No effort was made to see the perforator and to include the first dorsal interosseous muscle fascia or the first dorsal metatarsal artery itself. Dissection was, therefore superficial to the tendons of extensor hallucis brevis and longus. The flap was fashioned to cover the defect. A thick split-thickness graft from the groin or thigh was used to resurface the donor site.

\section{Case Presentations}

A 50 years old male patient had presented with a chronic ulcer over ulnar border and plantar aspect of great toe of left foot following a trauma sustained 4 months ago. After preoperative Doppler examination to confirm a perforator arising from DCA, a flap based upon first webspace perforator was elevated in the ratio of $1: 3$ to provide the coverage of the defect. A split thickness graft from the opposite thigh was used to cover the donor site raw area. The post-operative period was uneventful and the flap was healed well without any complication (Figures 1-5).
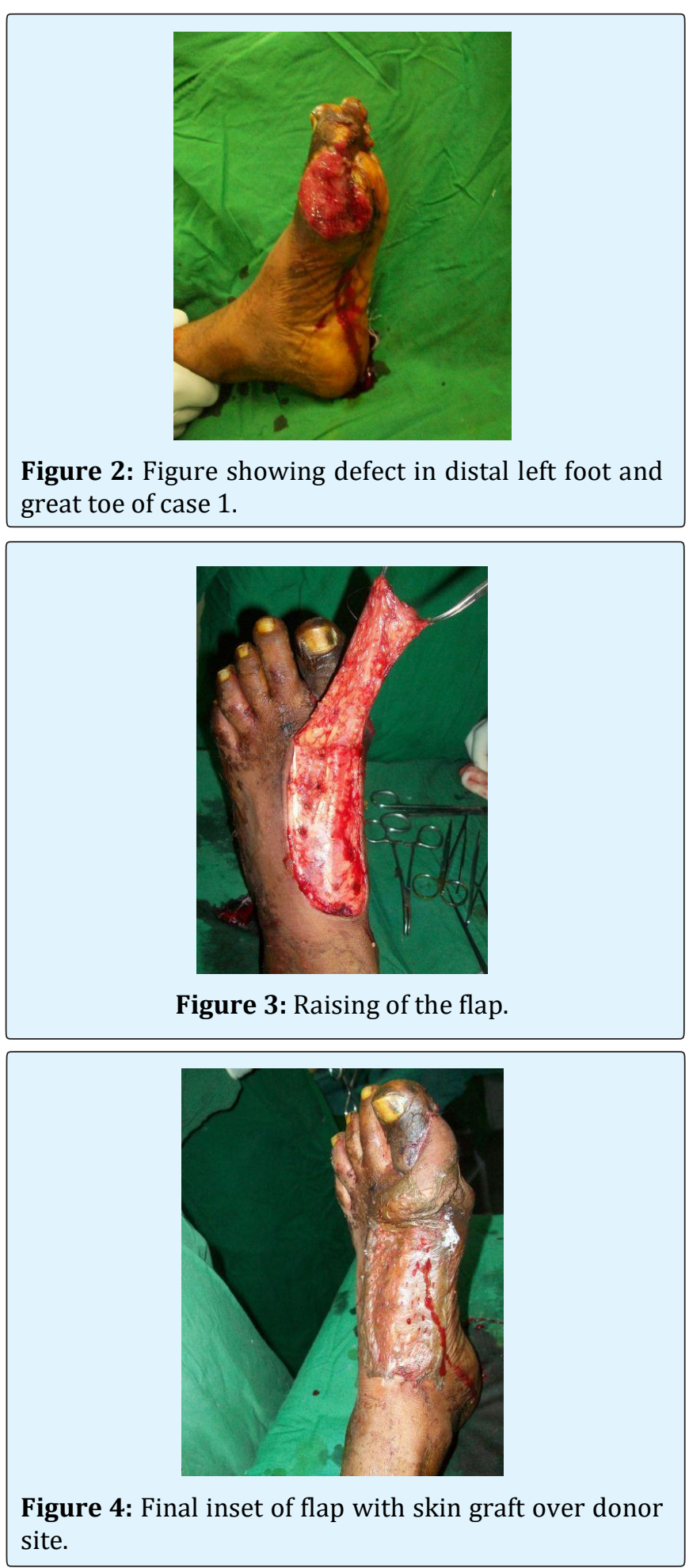


\section{International Journal of Transplantation \& Plastic Surgery}
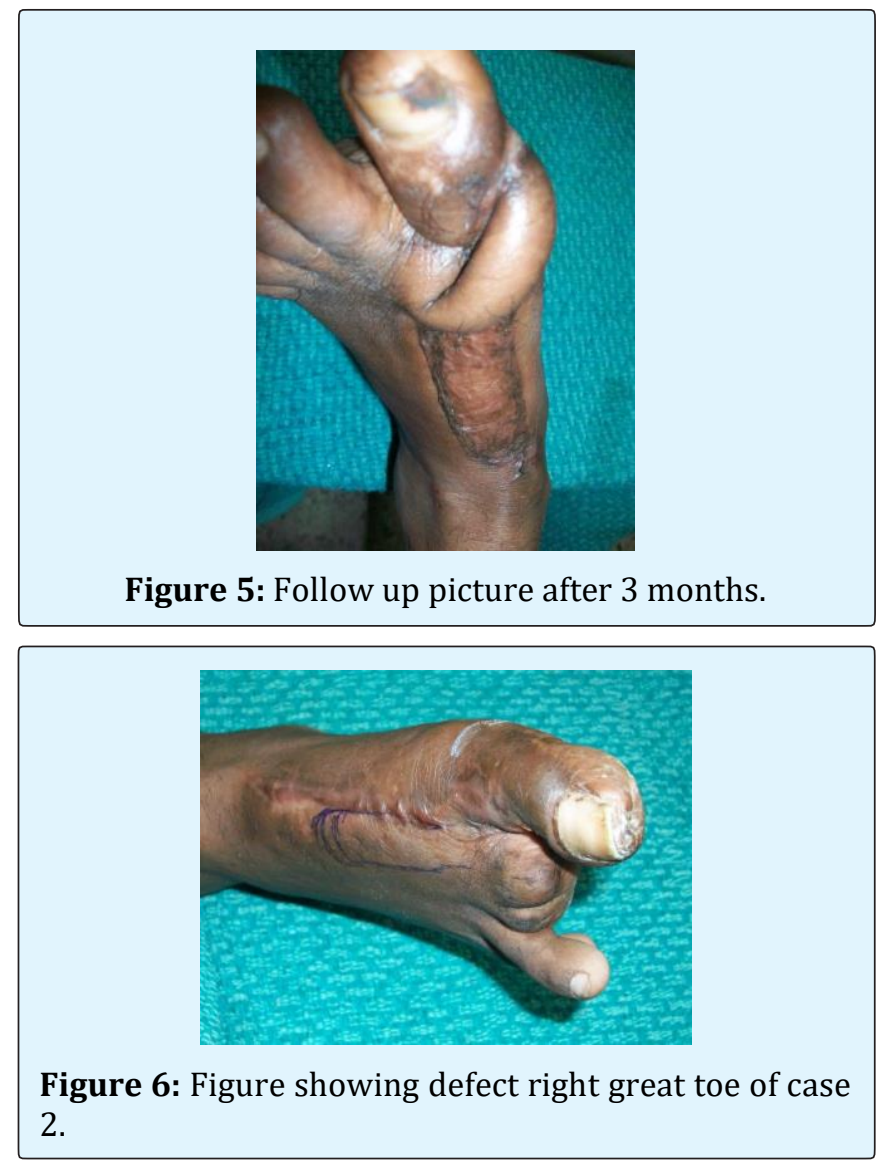

A 48 years old male patient who was a known diabetic presented with a chronic ulcer for 2 months following a trauma over the radial border of the great toe of right foot with a exposed proximal phalynx. Patient had post traumatic amputation of $2^{\text {nd }}$ and $3^{\text {rd }}$ toes. There again, a distally based first web space flap based upon a perforator arising from DCA was raised as an islanded flap to cover the defect. Again the flap was healed without any necrosis or infection (Figures 7-9).

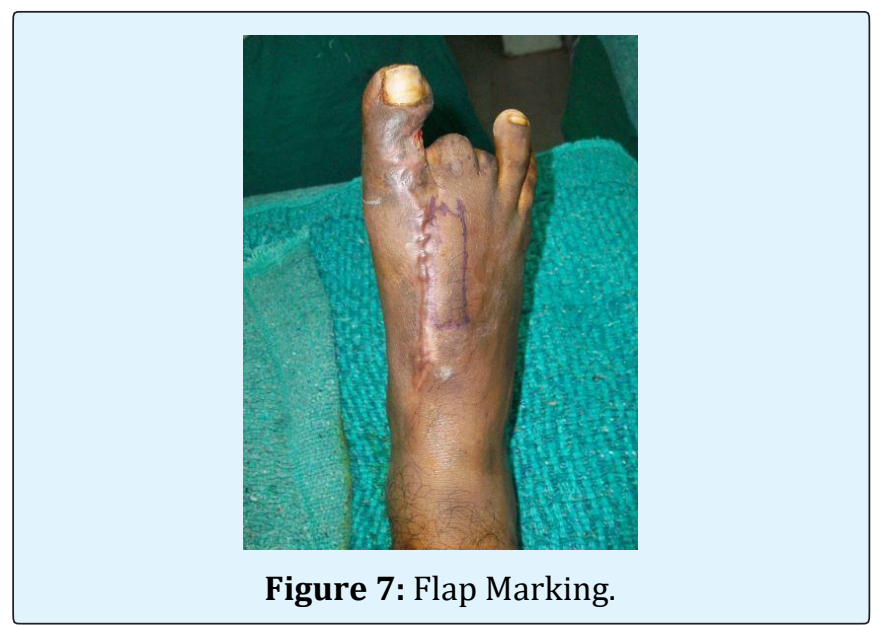

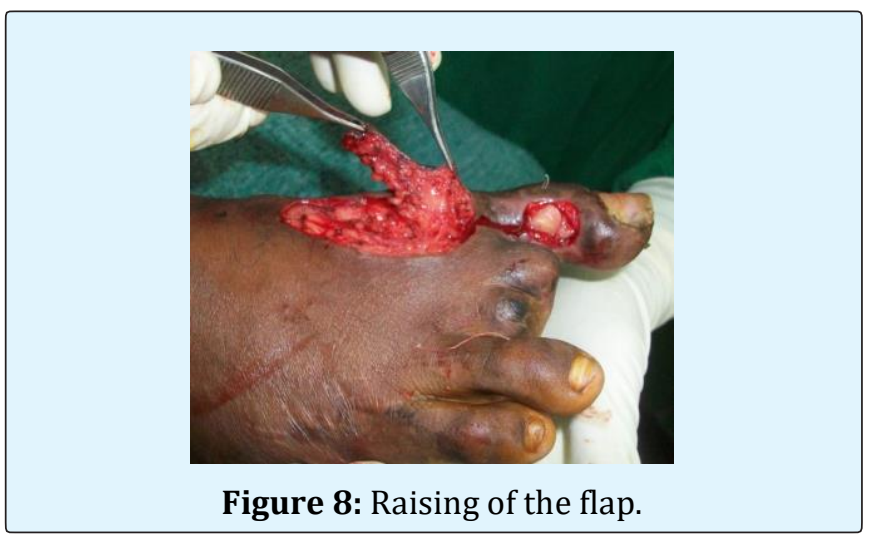

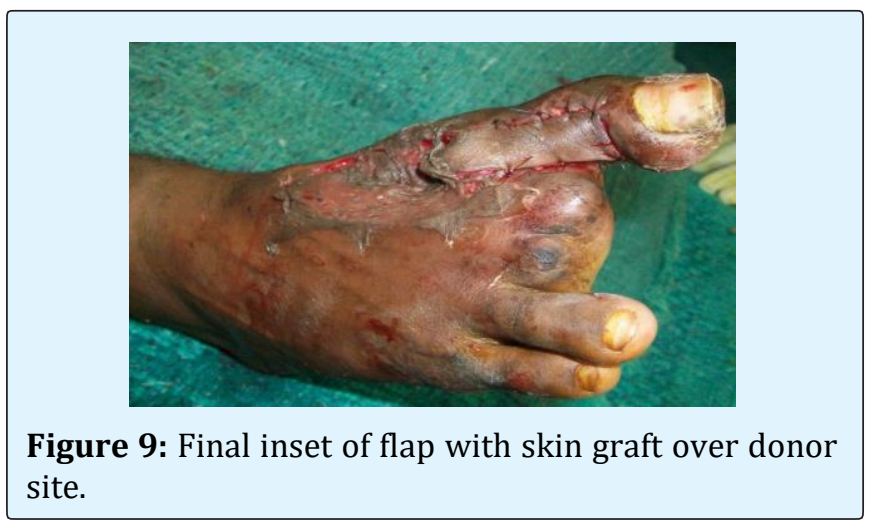

Another case was of a 16 years old girl who presented with post burn scar with contractures of $2^{\text {nd }}, 3^{\text {rd }}$ and $4^{\text {th }}$ toes of right foot with hyperextension of metatarsophalangeal joints of those toes following a burn injury sustained 4 years ago. She was operated with the release of the contractures with $\mathrm{K}$ wire fixation of the toes and a distally based first web space flap based upon a perforator arising from DCA was raised to cover the raw area over forefoot resulting after the release of the contracture. Flap was survived well with no significant complication (Figures 10-12).

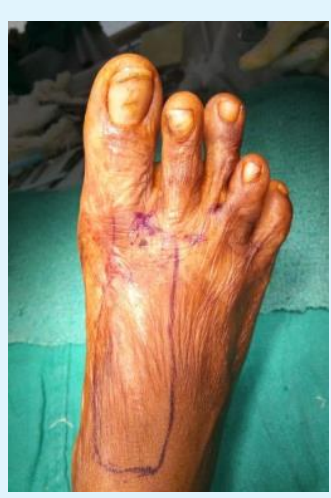

Figure 10: Figure showing post burn contracture of distal forefoot with contracture over toes in case 3 with flap marking. 


\section{International Journal of Transplantation \& Plastic Surgery}

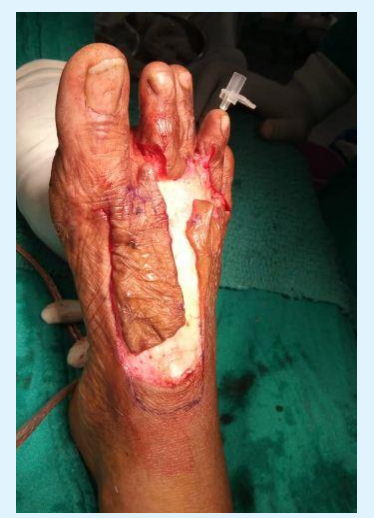

Figure 11: Contracture was released \& flap was raised.

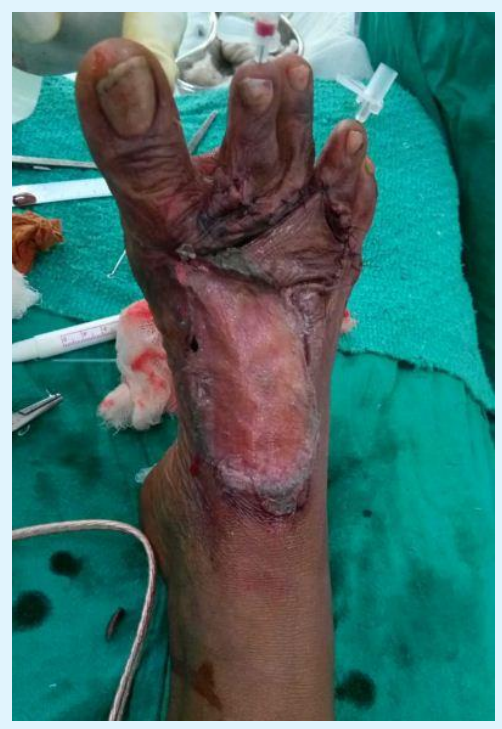

Figure 12: Final inset of flap with $\mathrm{K}$ wiring of the toes.

\section{Results}

Complications were noted in only two cases in the form of wound infections. In most of the cases, the postoperative period was remained uneventful despite incidence of wound infection that was noted in two of the cases, which were managed conservatively but all the flaps were healed completely.

\section{Discussion}

The coverage of defects of toes and the dorsum of forefoot have always been a challenging task. Moreover , the dorsal contractures following trauma or burn injury are very difficult to correct as often those lead to hyperextensions of metatarsophalangeal joints.

Release of contracture quickly exposes the underlying tendons and bones, making coverage of these defects with primary closure or skin graft unlikely. Local random flaps are unsuitable due to limited reach to the defect [5].

More often such patients present with chronic ulcer with osteomyelitic changes and fractured bones [6]. Ger R. in 1997 had suggested the coverage of such ulcers using pedicled muscle flaps and skin grafting [7]. Free flaps are also purposed to cover wide range of defects. Other options may include neurovascular first web flap, dorsalis pedis flap, toe wrap that are described in the literature [8].

The main limitation of using muscle flaps, free flaps ,free neurovascular first web flap is that these procedure require expertise, microsurgical instrumentation and availability of microscope. We found dorsalis pedis artery based flap unsuitable for the coverage of the defects in our study because of poor quality of native skin, donor site morbidity and taking into account the etiology of those defects [4]. First DMTA was also an option but the potential disadvantages with such flap included the donor site morbidity and insufficient venous outflow.

To cover the defect over toes and forefoot, the role of distally based flap based upon distal communicating artery is invaluable. The concept of the flap is similar to those based upon the web-spaces of the hand described by Earley $[9,10]$ and Colville $[11,12]$. The difference in the flap described in our study from those of mentioned by Earley $[9,10]$ was that the flap was based upon an unnamed perforator arising from the the distal communications between the first dorsal and plantar metatarsal arteries. An adequate arterial inflow is provided by the distal communicating artery from plantar system and the perforator arising from the distal communicating artery. Reliable venous outflow is provided by distal communication between superficial and deep venous system.

We had operated 10 patients with toe defects and contractures at the dorsum of the distal foot. A distally based first web space flap based upon a perforator arising from the distal communicating artery was used in all cases to cover the defects over the toes and distal fore foot. Wound infection was observed in only two of the cases, which were managed conservatively. 


\section{International Journal of Transplantation \& Plastic Surgery}

The mentioned flap in our study was based upon the perforator arising from the the distal communications between the first dorsal and plantar metatarsal arteries. In the past literature there has not been much description of such a flap. Moreover, such flap can also prove to be useful in case of injury to the anterior tibial artery as observed in one of our patient where DPA flap may not be an option to cover the great toe defect.

In most of our cases, there were poor quality of native skin, taking into account the etiology of those defects such as trauma, diabetes etc. The skin overlying DPA was found to be scarred but the skin over the used perforator was found to be comparatively of a better quality and less scarred. Therefore the chances of survival of the flap were more though there was some issue of venous congestion but it was not to a large extent.

\section{Conclusion}

With our study we concluded that a distally based flap can be reliably raised from the first web space based upon a perforator arising from the distal communication artery between FDMA and first PMTA to cover defects in distal foot.

\section{References}

1. Ashok RK, Rahul KP, Vinoth KP (2008) Coverage of defects over toes with distally based local flaps: A report of four cases. Indian J Plast Surg 41(1): 62-66.

2. McCraw JB, Furlow LT (1975) The dorsalis pedis arterialized flap: A clinical study. Plast Reconstr Surg 55(2): 177-185.
3. Huber JF (1941) The arterial network suplying the dorsum of the foot. Anatom Rec 80(3): 373-391.

4. Earley MJ, Milner RH (1989) A distally based first web flap in the foot. Br J Plast Surg 42(5): 507-511.

5. Attinger C (1995) Soft tissue coverage for lower extremity trauma. Orthop Clin North Am 26(2): 295334.

6. Attinger CE, Ducic I, Cooper P, Zelen CM (2002) The role of intrinsic muscle flaps of the foot for bone coverage in foot and ankle defects in diabetic and nondiabetic patients. Plast Reconstr Sur 110(4): 1047-1054.

7. Ger R (1997) The management of chronic ulcers of dorsum of foot by muscle transposition and free skin grafting. Br Jr Plast Surg 29(2): 199-204.

8. Cormack GC, Lamberty BGH (1986) The Arterial Anatomy of Skin Flaps. $1^{\text {st }}$ (Edn.), Edinburgh. London, Melbourne. New York: Churchill Livingstone.

9. Earley MJ (1986) The arterial supply of the thumb. first web and mdex finger and its surgical application. J Hand Surg Br 11(2): 163-174.

10. Earley MJ (1989) The first web hand flap. J Hand Surg Br 14(1): 65-69.

11. Colville J (1987) Island flap correction of syndactyly. Presented at the British Association of Plastic Surgeons. Summer Meeting. Edinburgh.

12. Colville J (1989) Syndactyly Correction. Br J Plastic Surg 42: 12-16. 